\title{
Primary Congenital Anomalies of the Coronary Arteries
}

\section{A Coronary Arteriographic Study in Western Turkey}

\author{
Ali AYDINLAR, ${ }^{1} \mathrm{MD}$, Davran ÇIÇEK, ${ }^{1} \mathrm{MD}$, Tunay ŞENTÜRK, ${ }^{1} \mathrm{MD}$, \\ Kani GEMICI, ${ }^{1}$ MD, Osman Akın SERDAR, ${ }^{1}$ MD, Ali Rlza KAZAZOǦLU, ${ }^{1}$ MD, \\ Ethem KUMBAY, ${ }^{1} \mathrm{MD}$, and Jale CORDAN, ${ }^{1} \mathrm{MD}$
}

\section{SUMMARY}

Coronary artery anomalies are found in $0.6 \%$ to $1.5 \%$ of coronary angiograms. Angiographic recognition of these vessels is important because of their clinical significance and importance in patients undergoing coronary angioplasty or cardiac surgery.

We reviewed the database of the Cardiac Catheterization Laboratory of Uludağ Medical University in Bursa, Turkey. All patients who were subjected to coronary angiography from 1994 to 2001 were included.

The study included 12,059 patients who underwent diagnostic coronary arteriography during the 8 year period. One hundred patients had primary congenital coronary anomalies. Ninty-five (95\%) of the patients had anomalies of origin and distribution while five (5\%) had coronary artery fistulae. The left main coronary artery (LMCA) was the most common anomalous vessel involved (forty-eight (48\%) of the patients). An LMCA distribution anomaly was observed in these 48 patients. An anomalous right coronary artery (RCA) was the second most common anomaly, seen in twenty-two (22\%) of the patients. An anomalous circumflex artery $(\mathrm{Cx})$ was the third most common anomaly, seen in seventeen. Five patients had a coronary artery fistulae. The fistulae in our series were small without significant shunt circulation.

Primary congenital coronary anomalies are isolated lesions and generally have no relation with other congenital heart diseases. They do not appear to be associated with an increased risk for development of coronary atherosclerosis. Angiographic recognition of these vessels is important because of their clinical significance and importance in patients undergoing coronary angioplasty or cardiac surgery. (Int Heart J 2005; 46: 97-103)

Key words: Coronary artery anomalies, Coronary artery fistulae, Coronary angiography

ANGIOGRAPHIC recognition of anomalous coronary arteries is important for the appropriate diagnosis and management of patients with or without atherosclerotic coronary artery disease. Congenital coronary artery anomalies are present at birth, but relatively few are symptomatic during childhood.

From the ${ }^{1}$ Department of Cardiology, Uludag University School of Medicine, Bursa, Turkey.

Address for correspondence: Ali Aydinlar, MD, Department of Cardiology, School of Medicine, Uludag University Görükle, Bursa, 16059 Turkey.

Received for publication March 10, 2004.

Revised and accepted July 22, 2004. 
Most anomalies are encountered as incidental findings during coronary arteriography or at autopsy. ${ }^{1)}$

Coronary artery anomalies are found in $0.6 \%$ to $1.5 \%$ of coronary angiograms (Table I) ${ }^{1-11)}$ Cardiologists, surgeons, and anatomists have been interested in coronary artery anomalies for many years. With the increasing frequency of coronary angiographies since the 1970s, these pathologies have been seen more often. Various anomalies have been described since the 18th century, both in clinical and pathologic studies, but the first landmark article, attempting a comprehensive classification, was published by Ogden in 1969, to which most authors refer, providing the basic nomenclature from which the terminology has been developed. ${ }^{10)}$ It is of course somewhat problematic to describe any finding as "anomalous" without a solid description of what is "normal" and what constitutes a variant of normal. In order to describe the norm, it was necessary first to develop criteria for systematic analysis. As Angelini stated in his 1989 article, normal anatomy should include $99 \%$ of the population. ${ }^{12)}$ For this reason, all the anomalies described in the literature on this subject have some degree of relativity, and most of them do not result in any clinical pathologies. The systematic anatomic approaches developed by Angelini and later by Khatami, et al, ${ }^{13)}$ are probably the most valid classification for coronary artery anomalies. Both classifications are very similar. According to these schemes, coronary artery anomalies can be defined as:

- Anomalous pulmonary origins of the coronary arteries

- Anomalous aortic origins of the coronary arteries

- Congenital atresia of coronary arteries

- Coronary artery bridging

- Coronary arteriovenous fistulas

- Coronary artery aneurysms

- Coronary stenosis.

Table I. Incidence of Coronary Artery Anomalies

\begin{tabular}{|c|c|c|c|}
\hline Authors & Total No. Patients & No. of Cor. Anom. & Ang. Incidence (\%) \\
\hline Yamanaka and Hobbs ${ }^{9)}$ & 126,595 & 1,686 & 1.3 \\
\hline Engel, et $a l^{4)}$ & 4,250 & 51 & 1.2 \\
\hline Chaitman, $e t a l^{3)}$ & 3,750 & 31 & 0.83 \\
\hline Baltaxe and Wilson ${ }^{5)}$ & 1,000 & 9 & 0.9 \\
\hline Kimbiris, et $a l^{2)}$ & 7,000 & 45 & 0.64 \\
\hline Donaldson, et $a l^{6)}$ & 9,153 & 82 & 0.9 \\
\hline Wilkins, et $a l^{7}$ & 10,661 & 83 & 0.78 \\
\hline Topaz, et $a l^{8)}$ & 13,010 & 80 & 0.61 \\
\hline This study & 12,059 & 100 & 0.8 \\
\hline
\end{tabular}

No = number Cor = coronary Ang = angiography; Anom = anomalies. 
Today, this classification is modified to be used in clinical practice and coronary artery anomalies have been divided in two groups, Group A: anomalies of origin and distribution, and Group B: intercoronary communications and coronary artery fistulae. We classified the coronary artery anomalies anatomically into two major groups with consideration of the previous studies. In this trial, our aim was to find the incidence of primary congenital coronary artery anomalies in patients who underwent coronary angiography for any reason in the west part of Turkey.

\section{MethodS}

We reviewed the database of the Cardiac Catheterization Laboratory of Uludağ Medical University in Bursa, Turkey. All patients who underwent coronary angiography from 1994 to 2001 were included. The catheterization reports were analyzed, and those with anomalous coronary arteries were selected for further assessment. The films were reviewed by three independent investigators before being finally classified. In case of any difference of opinion, a consensus was reached after discussion. Patients with coronary anomalies occurring as part of a complex congenital heart disease were not included in this study. The study included 12,059 patients who underwent routine coronary arteriography during the 8 year study interval to determine the incidence of coronary artery anomalies.

\section{RESUlts}

Patient population: The study included 12,059 patients who underwent diagnostic coronary arteriography during the study period. One hundred patients had primary congenital coronary anomalies. The indication for arteriography was evaluation of coronary artery disease in all the patients.

Incidence: The overall incidence of primary congenital coronary anomolies was $0.8 \%$ among patients undergoing diagnostic coronary arteriography; this is in agreement with the $0.6-1.5 \%$ incidence reported in different series (100 out of 12,059 patients). ${ }^{1-11,14,15)}$ Ninty-five patients $(95 \%)$ had anomalies of origin and distribution, while five (5\%) had coronary artery fistulae (Table II). LMCA was the most common anomalous vessel, involved in forty eight (48\%) patients. In 48 patients we found an LMCA distribution anomaly. An anomalous RCA was the second most common anomaly ( $22 \%$ of the patients). An anomalous Cx was the third most common anomaly seen $(17 \%)$. The angiographically detected coronary artery anomalies, according to the systematic analysis scheme proposed by Angelini and Khatami, were as follows: 
Table II. Incidence of Coronary Artery Anomalies

\begin{tabular}{lccc}
\hline & Number of patients & Angiographic incidence (\%) & Anomaly incidence (\%) \\
\hline Total coronary arteriograms & 12059 & - & - \\
Total coronary anomalies & 100 & 0.8 & - \\
Anomalies of origin and distribution & 95 & 0.7 & 95 \\
Coronary artery communications and fistulae & 5 & 0.04 & 5 \\
\hline
\end{tabular}

Anomalous pulmonary origins of the coronary arteries: In our trial, we did not find a coronary artery originating from the pulmonary artery.

Anomalous aortic origins of the coronary arteries: In 48 patients, there were no LMCA. Thirty-eight had different origins of the $\mathrm{Cx}$ and left anterior descending artery (LAD). Nine originated from the right sinus of Valsalva (RSV) and 1 from the RCA (single coronary artery). There were 22 RCA origin and distribution anomalies. Seven originated from the LSV and 3 from the LAD. In 8 patients, the RCA and conus artery had separate origins. The RCA was non-dominant in 4 patients. There were $17 \mathrm{Cx}$ artery origin and distribution anomalies, 11 of which originated from the RSV and 6 from the RCA. There were 8 LAD origin and distribution anomalies. The LAD originated from the RSV and the RCA in one patient each, was rudimentary in one, and 5 patients had a double LAD.

Congenital atresia of the coronary arteries: There was no atretic coronary artery in our patients.

Coronary artery bridging: We detected 125 instances of coronary artery bridging, 85 of which were at the LAD and 40 at the RCA and Cx. Only 7 had a stenosis over $80 \%$ and were symptomatic.

Coronary arteriovenous fistulas: Abnormal distal connections or terminations were included in this subgroup. Coronary artery fistulae were observed in 5 patients. The fistulae we found in our series were small and without significant shunt circulation. These were between the RCA and right atrium, LAD septal 1 and coronary sinus, LAD and pulmonary artery, LAD and left ventricle, and RCA and coronary sinus.

\section{DISCUSSION}

Coronary artery anomalies were found in $0.6 \%$ to $1.5 \%$ of the coronary angiograms described in the literature. Of these, $90 \%$ are abnormalities in the origin or distribution of a coronary artery and $10 \%$ are abnormal fistulas. Coronary anomalies are often classified as benign or clinically significant: most are benign. ${ }^{9)}$ The largest trial was that reported by Yamanaka and Hobbs from the Mayo Clinic. A total of 126,595 coronary angiography procedures were exam- 
ined retrospectively and the incidences of primary congenital anomalies of the coronary arteries were reported. ${ }^{9)}$ They reported that $80 \%$ of congenital anomalies of the coronary arteries are benign while $20 \%$ are clinically significant. ${ }^{9)}$ The most common are separate ostia of the LAD and Cx. ${ }^{9)}$ The most common anomaly in our trial was the same as this large trial. The $\mathrm{Cx}$ may arise from the right coronary sinus or as an early branch of the RCA. When present, the Cx virtually always travels behind the aorta to lie in the left atrioventricular groove. In our population, 11 patients had a Cx originating from the RSV and 6 from the RCA. Rarely, there may be no Cx: in this case, a superdominant RCA supplies the entire left atrioventricular groove and left posterolateral wall. All of these anomalies are benign and the angiographer must remember these. ${ }^{1)}$

The most common clinically significant anomaly is a coronary artery that originates from the contralateral aortic sinus. That is, the left main or LAD from the right sinus of Valsalva or the RCA from the left sinus of Valsalva. We had only one patient with a single coronary artery type RII (Modified Lipton's Classification). In patients with a single coronary artery, sudden death has been reported to be associated with a major coronary artery coursing between the aorta and main pulmonary artery. ${ }^{16)}$ Only 5 case reports of coronary intervention for a single anomalous coronary artery from the English ${ }^{17-21)}$ and 2 cases from the Japanese literature have been published. ${ }^{22}$

It is important to identify the course as it relates to the great vessels, because if it courses between the aorta and the pulmonary artery symptoms may occur. ${ }^{9)}$

A coronary artery may arise from the pulmonary artery. Most commonly, this is the LMCA, less commonly the LAD, and least commonly the RCA. Nearly $90 \%$ of patients with these anomalies die during infancy. If the patient survives, the anomalous artery fills retrogradely through collaterals and drains into the pulmonary artery (left to right shunt). This condition may cause angina, infarction, and heart failure: it warrants surgical repair (ligation and grafting or reanastomosis to the aorta or subclavian artery. ${ }^{9}$ In our trial, we worked on adult patients so there were no arteries originating from the pulmonary artery.

A coronary artery fistula is an abnormal connection between one of the coronary arteries and another structure, most commonly a venous structure or a chamber on the right side of the heart. The RCA is the site of the fistulae in 55\% of the patients. The majority of coronary artery fistulas empty into the right ventricle, right atrium, or coronary sinus. Less common are fistulas that drain into the pulmonary artery, left atrium, or left ventricle. Generally, the shunt is small, the myocardial blood flow to the terminal branches of the involved coronary artery is not compromised, and the patients are asymptomatic. However, if the shunt is large, pulmonary hypertension, congestive heart failure, bacterial endocarditis, rupture, and myocardial ischemia in the terminal portion of the involved coronary 
artery can occur. ${ }^{9)}$ The 5 fistulas we found in our series were small and without significant shunt circulation.

Coronary artery anomalies are rare causes of sudden death. Some of these anomalies have a risk of sudden death. An LMCA orginating from the pulmonary artery is not rare in congenital lesions, ${ }^{23)}$ and is associated with a high death rate in infants and children if surgery is not performed. ${ }^{24)}$

Arteriovenous fistulas are rarely seen and have lower death rates compared to the other coronary artery anomalies. An RCA originating from the LSV has been reported to be correlated with sudden death. ${ }^{25,26)}$

Congenital hypoplastic, stenotic, or atretic LMCA are rare anomalies and have been found to be related to myocardial infarction but not sudden death. ${ }^{25}$ )

Conclusions: Primary congenital coronary anomalies are isolated lesions and generally have no relation with other types of congenital heart disease. ${ }^{23)}$ They do not appear to be associated with an increased risk for development of coronary atherosclerosis. ${ }^{28)}$ Angiographic recognition of these vessels is important because of their clinical significance and importance in patients undergoing coronary angioplasty or cardiac surgery. ${ }^{29,30)}$ Some coronary artery anomalies have been correlated with sudden death, myocardial infarction, and anginal syndromes, and they need to be treated.,25)

\section{REFERENCES}

1. Kardos A, Babai L, Rudas L, et al. Epidemiology of congenital coronary artery anomalies: a coronary arteriographic study on a central European population. Cathet Cardiovasc Diagn1997; 42: 270-5.

2. Kimbiris D, Iskandrian AS, Segal BC, Bemis CE. Anomalous aortic origin of coronary arteries. Circulation 1978; 58: 606-15.

3. Chaitman BR, Lesperance J, Saltiel J, Bourassa MG. Clinical, angiographic, and hemodynamic findings in patients with anomalous origin of the coronary arteries. Circulation 1976; 53: 122-31.

4. Engel HJ, Torres C, Page HL Jr. Major variations in anatomical origin of the coronary arteries: angiographic observations in 4,250 patients without associated congenital heart disease. Cathet Cardiovasc Diagn 1975; 1 : 157-69.

5. Baltaxe HA, Wixson D. The incidence of congenital anomalies of the coronary arteries in the adult population. Radiology 1977; 122: 47-52.

6. Donaldson RM, Raphael M, Rodley-Smith R, Yacoub MH, Ross DN. Angiographic identification of primary coronary anomalies causing impaired myocardial perfusion. Cathet Cardiovasc Diagn 1983; 9: 237-49.

7. Wilkins CE, Betancourt B, Mathur VS, et al. Coronary artery anomalies: a review of more than 10,000 patients from the clayton cardiovascular laboratories. Tex Heart Inst J 1988; 15: 166-73.

8. Topaz O, DeMarchena R, Perin E, Sommer LS, Mallon SM, Chahine RA. Anomalous coronary arteries: angiographic findings in 80 patients. Int J Cardiol 1992; 34: 129-38.

9. Yamanaka O, Hobbs RE. Coronary artery anomalies in 126,595 patients undergoing coronary arteriography. Cathet Cardiovasc Diagn 1990; 21: 28-40.

10. Ogden JA. Congenital anomalies of the coronary arteries. Am J Cardiol 1970; 25: 474-9.

11. Page HL Jr, Engle HJ, Campbell WB, Thomas CS Jr. Anomalous origin of the left circumflex coronary artery. Recognition, angiographic demonstration and clinical significance. Circulation 1974; 50: 768-73. 
12. Angelini P. Normal and anomalous coronary arteries: definitions and classification. Am Heart J 1989; 117: 418-34. (Review)

13. Dodge-Khatami A, Mavroudis C, Backer CL. Congenital Heart Surgery Nomenclature and Database Project: anomalies of the coronary arteries. Ann Thorac Surg 2000; 69: 270-97.

14. dc Marchena EJ, Russo CD, Wozniak PM, Kessler KM. Compression of an anomalous left circumflex coronary artery by a bioprosthetic valve ring. J Cardiovasc Surg 1990; 31: 52-4.

15. Cieslinski G, Rapprich B, Kober G. Coronary anomalies: incidence and importance. Clin Cardiol 1993; 16: 711-5.

16. Lipton MJ, Barry WH, Obrez I, Silverman JF, Wexler L. Isolated single coronary artery: diagnosis, angiographic classification, and clinical significance. Radiology 1979; 130: 39-47.

17. Chan CN, Berland J, Cribier A, Letac B. Angioplasty of the right coronary artery with origin of all three coronary arteries from a single ostium in the right sinus of Valsalva. Am Heart J 1993; 126: 985-7.

18. Lawton J, McGrath J, Jones JS, Dehmer GJ. Treatment of coronary artery disease in an anomalous coronary artery by placement of an intracoronary stent. Cathet Cardiovasc Diagn 1997; 41: 185-8.

19. Hsu LA, Chu PH, Ko YS, Ko YL, Chiang CW. Transluminal coronary angioplasty and stenting in a patient with single coronary artery and acute myocardial infarction. Changgeng Yi Xue Za Zhi 1997; 20: 299-303.

20. Gambhir DS, Singh S, Bharadwaj S, Arora R. Rotablation and elective stenting of stenosis in the left anterior descending coronary artery arising from an anomalous single coronary artery. Indian Heart J 2000; 52: 459-60.

21. Stefenelli T, Wutte M, Madl C, Weissel M. Emergency angioplasty and stent deployment for acute occlusion of an anomalous single coronary artery (all three coronary arteries from one ostium in the right sinus of Valsalva). Wien Klin Wochenschr 2001; 113: 138-40.

22. Ohta H, Sumiyoshi M, Suwa S, et al. Primary coronary angioplasty with stenting for acute coronary syndrome in patients with isolated single coronary artery: a case report of 2 cases. Jpn Heart J 2003; 44: 759-65.

23. Levin DC, Fellows KE, Abrams HL. Hemodynamically significant primary anomalies of the coronary arteries. Angiographic aspects. Circulation 1978; 58: 25-34. (Review)

24. Roberts WC, Siegel RJ, Zipes DP. Origin of the right coronary artery from the left sinus of valsalva and its functional consequences: analysis of 10 necropsy patients. Am J Cardiol 1982; 49: 863-8.

25. Frescura C, Bosso C, Thiere G, et al. Anomalous origin of the coronary arteries and risk of sudden death: a study based on an autopsy population of congenital heart disease. Hum Pathol 1998; 30: 595-6.

26. Walter BF. Exercise-related sudden death in young and old $(<30)$ conditioned subjects. In: Wenger-nk(ed) Exercise and Heart. Philadelphia, FA Davis, 1985; 9-73.

27. Cheitlin MD, De Castro CM, Mc Allister HA. Sudden death as a complication of anomalous left coronary origin from the anterior sinus of Valsalva, A not-so minor congenital anomaly. Circulation 1974; 50: 780-7.

28. Naveen G, Satendra T, Aditya K, Deepak Kumar G, Nakul S. Primary congenital anomalies of the coronary arteries: a coronary arteriographic study. Int J Cardiol 2000; 74: 39-46.

29. Bass TA, Miller AB, Rubin MR, Stowers SA, Perryman RA. Transluminal angioplasty of anomalous coronary arteries. Am Heart J 1986; 112: 610-3.

30. Topaz O, DiSciascio G, Goudrean E, et al. Coronary angioplasty of anomalous coronary arteries: notes on technical aspects. Cathet Cardiovasc Diagn 1990; 21: 106-11. 